www.jmscr.igmpublication.org

Index Copernicus Value: 79.54

ISSN (e)-2347-176x ISSN (p) 2455-0450

crossref DOI: https://dx.doi.org/10.18535/jmscr/v7i3.228

\title{
Assessment of Shoulder Girdle Muscles Strength and Functional Performance in Fast Cricket Bowlers
}

\author{
Authors \\ Dr Pranali Desai ${ }^{*}$, Dr Ujwal Yeole ${ }^{2}$, Akshay Waghmare ${ }^{3}$, Dr Nilesh Andhare \\ ${ }^{1}$ Assistant Professor, Tilak Maharashtra Vidyapeeth, Pune \\ ${ }^{2}$ Associate Professor \& Principal, Tilak Maharashtra Vidyapeeth, Pune \\ ${ }^{3}$ Fourth Year BPT, Tilak Maharashtra Vidyapeeth, Pune \\ ${ }^{4}$ Assistant Professor, Tilak Maharashtra Vidyapeeth, Pune \\ *Corresponding Author \\ Dr Pranali Pradeep Desai \\ Department of Physiotherapy, Tilak Maharashtra Vidyapeeth, Pune, India \\ Contact no.9082291806, Email: pranalidesai15@gmail.com
}

\begin{abstract}
Background: Fast cricket bowlers have a high risk of shoulder injuries. As fast bowling in cricket involves an early run-up, numerous rotations and circumduction of a straight arm about the glenohumeral joint to impel a ball at a batsman. Which may be caused by factors like Shoulder distraction forces, abnormal postural adaptivity, improper bowling techniques, and imbalanced physical demands?

Objectives: To assess the shoulder functional disability, shoulder girdle muscles strength and arm rotation speed using SPADI, sphygmomanometer and Tachometer respectively.

Methodology: 70 fast bowlers were included according to inclusion \& exclusion criteria and consent was obtained. The functional evaluation of shoulder was done by Shoulder pain and disability index (SPADI), strength of shoulder girdle muscles of internal rotators, external rotator and scapular retractor was assessed using sphygmomanometer and the arm rotation speed was measured by tachometer.

Results: Mean value of SPADI score was (69.72 \pm 12.869$)$ which showed close to the worst pain on disability index. The assessment for strength of shoulder girdle muscles showed mean value of internal rotators was (103.85 \pm 8.052$)$; for external rotator was $(104 \pm 11.869)$ and for scapular retractors was

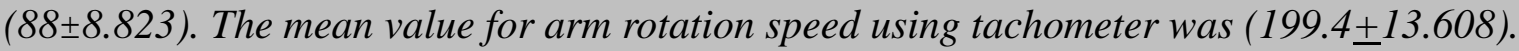

Conclusion: Study concludes that reduced strength of shoulder girdle muscle, poor the performance of fast cricket bowlers.

Keywords: Fast cricket bowlers, SPADI, Sphygmomanometer, Tachometer.
\end{abstract}

\section{Introduction}

Cricket is a non-contact sport. It has been regarded as a sport that is relatively injury free, but variety of injury can occur due to many factors such as high physical demands, poor bowling techniques, postural defects, and inadequate physical and physiological attributes ${ }^{1}$. Fast bowling is one of two main approaches to bowling in the sport of cricket. A faster release speed of ball helps to distract the batsman which affects the 
batsman's decision-making time and strokeexecution time that limits the runs scored or increases the chance of distracting the batsman ${ }^{2}$. Fast bowling in cricket involves activities about the glenohumeral joint as an early run-up, numerous rotations and circumduction of a straight arm to impel a ball at a batsman ${ }^{3}$. Fast bowling has been found to be a major cause of cricket injuries ${ }^{4}$. It involve recurring dynamic ballistic arm actions which will put a great deal of unconventional load on the shoulder rotator cuff muscles predisposing them to injuries. While performing bowling action there is continuous combination of external and internal rotations \& circumduction, during this the humeral head moves in various angles. During the acceleration phase of arm through concentric contraction internal shoulder rotators are involved while the external rotators are involved during the deceleration phase ${ }^{5}$. The back and shoulder seem to be the most affected by injury ${ }^{6}$. Many authors assume that this is probably because of the complex motor skills, the anthropometric profile and body composition of cricketers ${ }^{7}$.Shoulder girdle muscles weakness has been alarmed with Supraspinatous tear and shoulder impingement syndrome as well as anterior shoulder instability and superior laberal tear from anterior to posterior ${ }^{8}$.Weak internal rotators are related with humeral retroversion, posterior-inferior capsular contracture, and posterior rotator cuff tightness. Also, the ratio of strength between the external and internal rotators affects the balance of the glenohumeral joint. Muscle strength and length imbalance between these contrasting muscle groups increase the risk for shoulder injuries. This injury slowly affects the performance of the fast bowlers ${ }^{9}$. This small injury in future turn out to be the major cause which gives rise to conditions likes shoulder dislocations, rotator cuff injuries, tendinitis, and many more. Over the past two decades case reports and studies of incidents of cricket injuries indicate an increase in injuries ${ }^{7}$.

\section{Methodology}

Multicentred cross sectional community-based study was done. In which total no. of 70 fast bowlers were selected. Male fast bowlers between age group of 18-35 years who are performing fast bowling since three years at District level \& State level and those who willing to participate were included in the study. Individuals with recent shoulder / scapular fracture, cervical pain, rotator cuff injury, spinal injuries and with known deformities of spine were excluded.

The functional disability of shoulder joint was assessed by the SPADI, in which the pain \& disability score was obtained and the functional disability was assessed.

To assess strength of external rotators of shoulder, bowler was standing beside the wall, the cuff of Sphygmomanometer was placed to the wall, cuff filled with air by applying pressure till $20 \mathrm{mmhg}$, the resting mercury was observed at $20 \mathrm{mmh}$ then the bowler was asked to perform external rotation against the sphygmomanometer's cuff. The rising and steady mercury was observed at the end of the motion, this steady mercury level at particular mmhg/ level was obtained value for strength of external rotator. To assess the strength of internal rotators similar procedure was repeated. For assessing the strength of scapular retractors, bowler was in supine lying position on the cuff of sphygmomanometer with cuff between two scapular blades, bowler was instructed to perform retraction against the cuff. Three readings were taken and best one from 3 readings was consider as obtained value. To measure the arm rotation speed tachometer was placed in the bowler's dominant hand and was instructed to perform full arm rotation, the value obtained at the end of rotation on the digital screen was set as obtained value of arm rotation of every fast bowlers. Data was collected and statistically analyzed. 


\section{Data Analysis}

Statistical results were obtained using INSTAT

Table 1.1: Strength of shoulder girdle muscles using sphygmomanometer

\begin{tabular}{|l|c|c|c|}
\hline $\begin{array}{l}\text { Muscle } \\
\text { group }\end{array}$ & $\begin{array}{c}\text { Internal } \\
\text { rotators }\end{array}$ & $\begin{array}{c}\text { External } \\
\text { rotators }\end{array}$ & $\begin{array}{c}\text { Scapular } \\
\text { retractors }\end{array}$ \\
\hline $\begin{array}{l}\text { Standard } \\
\text { value }\end{array}$ & $190 \mathrm{mmhg}$ & $157 \mathrm{mmhg}$ & $\begin{array}{c}160 \\
\mathrm{mmhg}\end{array}$ \\
\hline $\begin{array}{l}\text { Mean } \\
\text { Obtained }\end{array}$ & 103.85 & 104 & 88 \\
value & \pm 8.052 & \pm 11.869 & \pm 8.823 \\
\hline
\end{tabular}

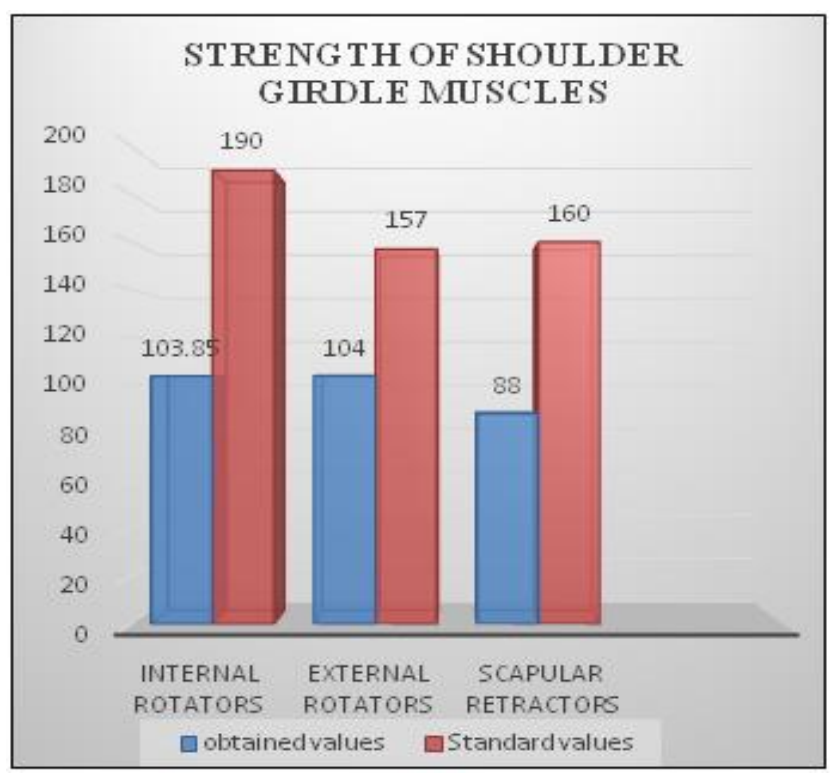

Graph no 1: strength of shoulder girdle muscles using sphygmomanometer

Interpretation: Mean value obtained of internal rotator $(103.85 \pm 8.052)$ for external rotator is $(104 \pm 11.869)$ and for scapular retractor is $(88 \pm 8.823)$.

Table no 2.1: SPADI Index Score

\begin{tabular}{|l|c|c|c|}
\hline $\begin{array}{l}\text { Content } \\
\text { of SPADI }\end{array}$ & Pain score & $\begin{array}{c}\text { Disability } \\
\text { score }\end{array}$ & Total score \\
\hline $\begin{array}{l}\text { Mean } \\
\text { value }\end{array}$ & $29.11 \pm 8.126$ & $44.87 \pm 5.376$ & $69.72 \pm 12.869$ \\
\hline
\end{tabular}

Interpretation: Mean value obtained for total score of SPADI $69.72 \pm 12.869$ which revels the more shoulder function disability

Table 3.1: SPADI, Sphygmomanometer, Tachometer score

\begin{tabular}{|l|c|c|c|c|}
\hline $\begin{array}{l}\text { SPADI } \\
\text { Index }\end{array}$ & $\begin{array}{c}\text { Internal } \\
\text { rotation }\end{array}$ & $\begin{array}{c}\text { External } \\
\text { Rotation }\end{array}$ & $\begin{array}{c}\text { Scapular } \\
\text { retraction }\end{array}$ & $\begin{array}{c}\text { Tacho } \\
\text { meter }\end{array}$ \\
\hline 69.72 & 103.85 & 104 & 88 & $199.4 \pm \underline{ \pm}$ \\
\pm 12.86 & \pm 8.052 & \pm 11.869 & \pm 8.823 & 13.608 \\
\hline
\end{tabular}

\section{Discussion}

The present study conducted with the aim to assess of shoulder girdle muscles strength and functional performance of fast cricket bowlers.

On the basis of inclusion criteria 70 fast cricket bowlers between the age group of 18-35 years were included in the study. Mean value for age was (23.01 \pm 2.624$)$. Amongst that $20 \%$ of players were from $15-20 \mathrm{yr}$. of age group, $57 \%$ of players were from $20-25 \mathrm{yr}$. of age group, $23 \%$ of players were from 25-30 yr. Of age group respectively. So most of the population of fast bowlers belongs from the age group of 20-25 yrs.

In present study, the functional evaluation assessment on SPADI score showed mean value $69.70 \pm 12.869$ (Table 1.1) which showed mean value close to the worst pain $\&$ disability index at shoulder. Paul et al (2004) in their study stated that the SPADI demonstrates good construct validity, correlating well with other regionspecific shoulder questionnaires ${ }^{10}$.

The obtained values for muscle strength using sphygmomanometer was $(103.85 \pm 8.052)$ for internal rotators, for external rotator was $(104 \pm 11.869)$ and for scapular retractors was (88 \pm 8.823$)$. Daniel R Perossa, Martin Dziak, Howard T Vernon, Kaye Hayashita, in their study stated the standard values in mmhg using sphygmomanometer for internal, external rotators and retractors. The normal value for internal rotators was $190 \mathrm{~mm} / \mathrm{hg}$. External rotators were $160 \mathrm{~mm} / \mathrm{hg}$ and for scapular retractors the normal value was $160 \mathrm{~mm} / \mathrm{hg}^{11}$. As compared to this normal value, the obtained values in present study are very less which indicates that the strength of shoulder girdle muscles in fast bowlers is less (Table 2.1). Alexandre Carvalho Barbosa et.al (2002) in their study stated that the ratio of strength between the external and internal rotators affects the balance of the glenohumeral joint which increase the risk for shoulder injuries ${ }^{7}$.

L.c. loramet.al (2005) in their study stated that research on the determinants of bowling speed has also become more prominent as faster bowlers release the ball to more uncertainty about hitting 
the ball in created in the batter'smind ${ }^{9}$. A faster bowler should possess good muscle power and endurance. Derbyshire, Denis in their study stated that number of other factors might play a more important role in the execution of a powerful throw for distance, such as the involvement of the total well-coordinated kinetic chain, and the throwing techniques ${ }^{12}$. Relationship between upper body strength and ball release speed which showed that bowlers with stronger shoulder depression and horizontal flexion bowled faster. In present study arm rotation speed was assessed using tachometer. In the present study the mean value for arm rotation speed using tachometer was (199.4+13.608).

Thus, the present study showed that a fast bowler reveals the low score on SPADI index reduce values for strength of shoulder girdle muscles and reduce rate of performance (Table 3.1).

\section{Conclusion}

This study concludes that reduced strength of shoulder girdle muscle, poor the performance of fast cricket bowlers.

\section{References}

1. D. Foster et. al, Back injuries to fast bowlers in cricket: A prospective study, Br.J.Sp. Med 1989 Sep;23(3) :150-154

2. Katharine L. et.al. Effect of Ball Weight on Speed, Accuracy, and Mechanics in Cricket Fast Bowling, Sports 2017,5 23 February 2017; Published: 28 February 2017

3. Dr. Nilesh Andhare et.al, Effect of Throwers Ten Program on Performance in Fast Bowlers "Randomized Control Trail, JMSCR Volume 06 Issue 12 December 2018

4. Ajit Surendra Dabholkar et al Scapular Associated Impairments in Bowlers Sports Science and Human performance, 978-935258-836-7, Dec 2015.
5. Codine Pet.al. Influence of sports discipline on shoulder rotator cuff balance. Med Sci Sports Exerc 1997; 29:1400-5.

6. Bruce C Elliott, Back injuries and fast bowler in cricket, January 2001, Journal of sports sciences 18 (12);983-91

7. Alexandre Carvalho Barbosa et al,Validity and reliability of shoulder strength assessment during scaption, internal rotation, external rotation using an anchored non-modified sphygmomanometer Human Movement, Vol. 19, No 2, Brazil.

8. Mabasa Xm et.al Isokinetic Strength of Shoulder Internal and External Rotators in Cricket Bowlers, SA journal of physiotherapy (2002) vol 58 no 2, South Africa.

9. LC loram et al, Determinants of Ball release speed in school boys, fast medium bowlers in cricket, Journal of Sports Medicine and Physical Fitness 2005 Dec;45(4):483-90.

10. Paul et al (2004)A comparison of four shoulder-specific questionnaires in primary care, Ann Rheum Dis 63;12931299

11. Daniel R Perossa et al., (1998). The intraexaminer reliability of manual muscle testing of the hip and shoulder with sphygmomanometer: A preliminary study of normal subjects. J Can Chiropr Assoc. 42(2). Canada.

12. Derbyshire, Denis, physical factors influencing the throwing action in netball and cricket players thesis ( $m$ sport $\mathrm{sc}$ (sportscience))-university of stellnbosch, 2007

13. Ujwal Yeole et al.2017, Effectiveness Of Throwers Ten Programme On Performance Of Hammer Throwers. Int J Recent Sci Res.8(12),pp22466-22469. 